\title{
COMPORTAMENTO EMPREENDEDOR E TRAJETÓRIA EMPRESARIAL DE FUNDADORES DE MPES EM BARÃO DE COCAIS/MG
}

Artigo recebido em: 01/09/2014. Artigo aprovado em: 27/07/2015.

\section{Wendel Alex Castro Silva - Faculdade Novos Horizontes ${ }^{1}$ Rosimar Aparecida da Fonseca - Faculdade Novos Horizontes ${ }^{2}$ Elisson Alberto Tavares Araújo - Banco do Brasil ${ }^{3}$}

Resumo: O objetivo do presente estudo foi identificar as Competências Comportamentais Empreendedoras (CCEs) presentes nos fundadores de empresas que influenciam sua trajetória empresarial no município de Barão de Cocais/MG, a partir da perspectiva de Bygrave (2004). A pesquisa é empíricodescritiva e qualitativa, sendo um estudo de casos múltiplos. Os dados foram analisados a partir de duas categorias de análise temáticas: caracterização dos entrevistados e das empresas, e trajetória empresarial a partir dos fatores pessoais, sociológicos, organizacionais e ambientais que influenciam no Processo Empreendedor. Os resultados demonstraram que a convivência com pessoas empreendedoras na família, aliada à percepção de uma oportunidade de negócio no município, foram fundamentais na decisão de torna-se empreendedor. As CCEs mais comuns foram: inovação, liderança, otimismo, iniciativa, habilidade de conduzir situações e utilizar recursos. As características pessoais, sociológicas, organizacionais e ambientais sugeriram interferir na formação do processo empreendedor, confirmando-se, parcialmente, o modelo de Bygrave, exceto as variáveis "insatisfação com o trabalho, ser demitido, idade, investidores, incubadoras e advogados", não apontadas pelos empreendedores. Portanto, essa teoria mostrou-se efetiva no estudo do comportamento dos fundadores das empresas da amostra.

Palavras-chave: Processo Empreendedor; Comportamento Empreendedor; Trajetória Empresarial; MPEs.

1 Endereço: Rua Alvarenga Peixoto, 1270. Santo Agostinho, Belo Horizonte - MG, 30180-121

E-mail: wendel.silva@unihorizontes.br

2 E-mail: rosimar.fonseca@yahoo.com.br

3 E-mail: elisson.araujo@unihorizontes.br

SILVA, W. A. L.; FONSECA, R. A. F.; ARAUJO, E. A. T. A. Comportamento empreendedor e trajetória empresarial de fundadores de MPES em Barão de Cocais/MG. Revista de Empreendedorismo e Gestão de Pequenas Empresas, v.4, n.2, 2015. 


\title{
ENTREPRENEUR BEHAVIOR AND CORPORATE TRAJECTORY OF FOUNDERS OF MSES IN BARÃO DE COCAIS / MG
}

\begin{abstract}
The aim of this study was to identify the CCEs present in the founders of companies that influence their corporate trajectory in the city of Barão de Cocais / MG, from the perspective of Bygrave (2004). The research is empirical-descriptive and qualitative, being a multiples cases study. The data were analyzed from two thematic categories of analysis: characterization of respondents and of businesses, and corporate trajectory from personal, sociological, organizational and environmental factors that influence the Entrepreneurial Process. The results showed that living with enterprising people in the family, coupled with the perception of a business opportunity in the city, were instrumental in the decision to become an entrepreneur. The most common CCEs were: innovation, leadership, optimism, initiative, ability to lead and make use resources. The personal, sociological, organizational and environmental characteristics suggest interfere in the formation of the entrepreneurial process, confirming partially the model Bygrave, except the variables "dissatisfaction with work, getting fired, age, investors, incubators and lawyers," not identified by entrepreneurs. Therefore, this theory proved to be effective on the behavior of the founders of the sample companies.
\end{abstract}

Keywords: Entrepreneurial Process; Entrepreneurial behavior; Corporate trajectory; MSEs.

\section{Introdução}

As micro e pequenas empresas (MPEs) possuem relevância no cenário socioeconômico do Brasil, já que funcionam como elemento de promoção social, pilar de estabilidade política, sendo impulsionadoras de desenvolvimento. As MPEs são responsáveis por gerar emprego e distribuir renda (SEBRAE/SC, 2009).

Nessa perspectiva, o empreendedorismo adquire destaque. Para Bygrave (2004), o empreendedorismo é núcleo da livre organização devido à geração de novos negócios, o que responde pela contribuição da dinâmica do mercado e, consequentemente, o desenvolvimento econômico. O empreendedorismo exibe consequências econômicas e sociais, sobretudo, na constituição de novos negócios e geração de novos produtos e serviços. O

SILVA, W. A. L.; FONSECA, R. A. F.; ARAUJO, E. A. T. A. Comportamento empreendedor e trajetória empresarial de fundadores de MPES em Barão de Cocais/MG. Revista de Empreendedorismo e Gestão de Pequenas Empresas, v.4, n.2, 2015. 
empreendedor é o principal responsável pelos recursos e busca 0 aproveitamento de oportunidades e a efetivação do empreendimento (ENOQUE, 2014).

Quando se analisa o empreendedorismo como processo, é possível explorar uma modificação de foco neste campo de estudo, pois o interesse estaria direcionado àquilo que o empreendedor executa, facilitando 0 conhecimento das práticas desenvolvidas pelos empreendedores (STEYAERT, 2007).

Entretanto, boa parcela das pesquisas sobre empreendedorismo (e.g. MACIEL, 2009; MARTINELLI; FLEMING, 2010; MACIEL; CAMARGOS, 2010) focam os condicionantes da mortalidade de MPEs, deixado de abordar os fatores que auxiliam na manutenção da longevidade empresarial.

Conforme pesquisa do DIEESE (2008), somente uma pequena parte das MPEs ultrapassa seus primeiros quatro anos operacionais. Tal fato possui relação com a qualidade do empreendedorismo nacional, a qual se reflete na taxa de descontinuidade das empresas. O Brasil estava em 9 lugar no ranking de descontinuidade em 2007, passando ao 23ํe em 2008.

A despeito da melhora, os dados indicam morte prematura desses negócios (GEM, 2008). O SEBRAE/MG, (2008) revela que em Minas Gerais, as MPEs são 99\% das empresas formais, tal qual a média nacional. Geram acima de 2,1 milhões de empregos: $65 \%$ dos postos de trabalho de MG. Sua taxa de mortalidade é uma das mais baixas do país.

As pesquisas sobre empreendedorismo colaboram com a construção teórica sobre o assunto, contribui para a compreensão do comportamento empreendedor e fomenta o processo empreendedor (CARNEIRO, 2008). É preciso conhecer como ocorre o processo, seus fatores críticos, o perfil, o comportamento e a trajetória dos empreendedores de sucesso, para que as estatísticas de mortalidade das empresas sejam alteradas, por meio de técnicas que possam ser utilizadas para o desenvolvimento dessas empresas (DORNELAS, 2005).

SILVA, W. A. L.; FONSECA, R. A. F.; ARAUJO, E. A. T. A. Comportamento empreendedor e trajetória empresarial de fundadores de MPES em Barão de Cocais/MG. Revista de Empreendedorismo e Gestão de Pequenas Empresas, v.4, n.2, 2015. 
Nessa perspectiva, Bygrave (2004) criou uma modelagem do processo empreendedor para explicar os passos de abertura de uma empresa por intermédio de características pessoais, sociológicas e ambientais. O modelo parte com a ideia do negócio. Após, um evento impulsionará seu começo, a implantação e o crescimento.

Vários estudiosos têm abordado o tema empreendedorismo com diferentes focos. Em relação ao comportamento empreendedor, Barros e Moreira (2005) analisaram a organização produtiva das MPEs atuantes no segmento do turismo e Carneiro (2008) descreveu a metodologia de Fuzzy para compreender o comportamento empreendedor.

Sobre o processo empreendedor, Boszczowski e Teixeira (2012) examinaram as fontes e o processo empreendedor de negócios sustentáveis pela abordagem de Bygrave e Filia (2012) estudou o processo empreendedor de Bygrave em um ambiente de aprendizagem: as incubadoras.

Quanto aos trabalhos sobre a trajetória empresarial, Greatti (2010) realizou uma análise comparativa de trajetórias empresariais no município de Maringá/PR e Fernandes (2013) investigou a trajetória de empreendedores na cidade de Brumadinho/MG, ancorado em Bygrave (2004).

Nesse cenário, a questão de pesquisa é a seguinte: quais são as CCEs presentes nos fundadores de empresas que influenciam sua trajetória empresarial no município de Barão de Cocais/MG a partir do modelo de Bygrave (2004)?

Sendo assim, a proposta deste artigo é a de identificar essas CCEs presentes nos fundadores de empresas que influenciam sua trajetória empresarial no município de Barão de Cocais/MG a partir do modelo de processo empreendedor de Bygrave (2004).

Este trabalho segue a seguinte estrutura: após a seção introdutória, a seção 2 expõe o referencial teórico. A seção 3 contempla os parâmetros metodológicos respeitados. Na seção 4 , são apresentados e discutidos os resultados. Já na seção 5 são reveladas as considerações finais e após, as referências.

SILVA, W. A. L.; FONSECA, R. A. F.; ARAUJO, E. A. T. A. Comportamento empreendedor e trajetória empresarial de fundadores de MPES em Barão de Cocais/MG. Revista de Empreendedorismo e Gestão de Pequenas Empresas, v.4, n.2, 2015. 


\section{Comportamento empreendedor}

O comportamento empreendedor é indispensável na geração de novos negócios. Por isso, é preciso analisar todos os aspectos relacionados ao comportamento e à cognição para alcançar clareza na compreensão do empreendedorismo (BARON, 2007).

A cultura, os hábitos e as necessidades de uma determinada comunidade influenciam no comportamento do empreendedor. Assim, os empreendedores assumem determinadas características do período e do lugar onde vivem. No entanto, tendo em vista a era eletrônica, os maiores empreendedores exercem influência em esferas superiores ao limites geográficos (FILION, 1999).

Neste aspecto, Dolabela (2008) considera o empreendedor como um ser que influencia e recebe a influência do ambiente, pois é um produto do meio. É um indivíduo que faz parte de um ambiente em que o empreendedor é visto positivamente, as pessoas terão motivação para criar seu próprio negócio. Portanto, as CCEs podem variar de um lugar para outro.

Segundo Filion (1999) quando existe um modelo empreendedor na família ou no meio no qual o indivíduo está inserido, aumentam as chances de apresentarem novos empreendedores. Borges e Lima (2012) mencionam que um sujeito empreendedor ou uma família empreendedora é capaz de combinar recursos, habilidade, conhecimento e competência para aproveitar as oportunidades do mercado. Do mesmo modo, em um ambiente estruturado em rede, em que a democracia e cooperação prevalecem, é propício ao desenvolvimento do empreendedor (DOLABELA, 2008).

Quando um indivíduo torna-se empreendedor, há uma prática e desenvolvimento de certas características para manutenção da atividade. Então, os empreendedores apreendem a partir do que fazem e, como as atividades mudam constantemente, eles também precisam mudar. Em função

SILVA, W. A. L.; FONSECA, R. A. F.; ARAUJO, E. A. T. A. Comportamento empreendedor e trajetória empresarial de fundadores de MPES em Barão de Cocais/MG. Revista de Empreendedorismo e Gestão de Pequenas Empresas, v.4, n.2, 2015. 
disso, o empreendedor assume diversos papéis durante a trajetória empresarial (FILION, 1999).

O comportamento empreendedor varia segundo a forma que 0 empreendedor percebe o ambiente. Assim, a partir do conhecimento de um determinado tipo de mercado, o empreendedor desenvolve um novo produto ou processo (FILION, 2000).

Ao conduzir os negócios, os empreendedores se deparam com desafios característicos de cada fase do empreendimento. Entretanto, as formas como lidam com esses problemas serão influenciada pelas características de personalidade de cada pessoa (DELLA BRUNA JUNIOR, 2012).

A maneira como os empreendedores constroem a visão do empreendimento foi definida por Filion (1999) em três categorias: a primeira, a visão emergencial, refere-se ao conceito de futuros produtos ou serviços; a segunda trata-se da visão central demonstrada a partir dos resultados alcançados no mercado por meio de uma organização necessária para o sucesso do empreendimento; e a terceira é a complementar, onde há as atividades necessárias para que a visão central seja alcançada.

A pesquisa sobre a caracterização do empreendedor em termos de comportamento tem sido debatida para enfatizar seu perfil heterogêneo. Nas pesquisas pioneiras, na qual havia a predominância de estudos na dimensão individual (GARTNER, 1985), a análise seguia a comparação entre empreendedores e não empreendedores. Mas esse foco foi incapaz de explicar o evento empreendedor e suas variações (BYGRAVE, 2004).

Daí surgiu a perspectiva do empreendedorismo como processo (ENOQUE, 2014). A partir da presença de fatores contextuais acerca do sujeito empreendedor, tornou-se possível descrever um processo empreendedor (MOROZ; HINDLE, 2012). Segundo Della Bruna Junior et al. (2012), a análise desse processo amplia o entendimento dos elementos concernentes à evolução dos empreendimento e do comportamento empreendedor.

SILVA, W. A. L.; FONSECA, R. A. F.; ARAUJO, E. A. T. A. Comportamento empreendedor e trajetória empresarial de fundadores de MPES em Barão de Cocais/MG. Revista de Empreendedorismo e Gestão de Pequenas Empresas, v.4, n.2, 2015. 


\section{Modelo do processo empreendedor}

Os eventos que antecedem a criação de uma organização, como a identificação da oportunidade, os recursos financeiros e humanos aliados ao evento de criação e seu percurso para o desenvolvimento e sobrevivência, é denominado, por Bygrave (2004), como processo empreendedor. Para Dornelas (2005), a decisão de tornar-se empreendedor pode ocorrer considerando o ambiente externo e os fatores pessoais, sociológicos e organizacionais em conjunto ou isoladamente.

Segundo Carpintéro e Bacic (2001), o processo empreendedor é o resultado das interações pessoais, culturais e sociais, além de integrar o processo de desenvolvimento social e econômico. Tal processo pode ser representado pela interação entre fundadores e sucessores de empresas familiares e, nessa perspectiva, é o resultado de uma ação coletiva (BONCLER; HLADY; VERSTRAETE, 2006).

Por outro lado, Gartner (1985), Shapero e Sokol (1982), Ronen (1983), Anderson, (2000), Bygrave (2004) e Dornelas, (2005), assinalam que o processo empreendedor é compostos por inúmeros estágios de evolução, como criação, crescimento e consolidação da organização. A fase de sobrevivência é considerada uma das mais difíceis do processo.

A duração e o número de etapas do processo empreendedor apresentam variações na literatura. No que se refere à duração, Gartner (1985) e Ronen (1983) consideram que o processo empreendedor acaba com o início da produção e a introdução do produto no mercado. A partir deste momento, inicia-se a fase gerencial do negócio separada da ação empreendedora. No entanto, essa linha limita a compreensão do processo empreendedor ao restringilo simplesmente ao evento empreendedor que acontece em um período curto de tempo, enquanto o processo empreendedor ocorre em um período mais longo e de difícil delimitação de sua última fase (ANDERSON, 2000).

SILVA, W. A. L.; FONSECA, R. A. F.; ARAUJO, E. A. T. A. Comportamento empreendedor e trajetória empresarial de fundadores de MPES em Barão de Cocais/MG. Revista de Empreendedorismo e Gestão de Pequenas Empresas, v.4, n.2, 2015. 
Devido à complexidade do evento empreendedor, Gartner (1985) criou conceitos para explicá-lo, que consideram todos os aspectos que envolvem o empreendedorismo e a criação de uma nova organização. Essa teoria abarca três dimensões - indivíduo, ambiente e organização.

Gartner (1985) argumenta que as dimensões do evento empreendedor devem ser analisadas em conjunto com suas variáveis para estabelecer comparações e debates que permitam predizer o comportamento empreendedor, possibilitando estabelecer uma teoria consistente sobre a criação de organizações.

O modelo de processo empreendedor de Bygrave (2004), adotado como referência teórica nesta pesquisa, é composto por quatro etapas: inovação, evento inicial, implementação e crescimento. Cada etapa sofre influência de fatores pessoais, sociológicos, ambientais e organizacionais. Nas fases de inovação do evento inicial (estimula a criação do negócio) e de implementação da empresa, são essenciais as características pessoais e ambientais. É preciso lembrar que ainda estão presentes as características sociológicas. Já na fase de crescimento do negócio estão presentes os fatores organizacionais em conjunto com os pessoais e ambientais apresentados na etapa de implementação.

A figura 1 apresenta o modelo proposto por Bygrave (2004) por meio das variáveis que interferem no processo empreendedor.

SILVA, W. A. L.; FONSECA, R. A. F.; ARAUJO, E. A. T. A. Comportamento empreendedor e trajetória empresarial de fundadores de MPES em Barão de Cocais/MG. Revista de Empreendedorismo e Gestão de Pequenas Empresas, v.4, n.2, 2015. 


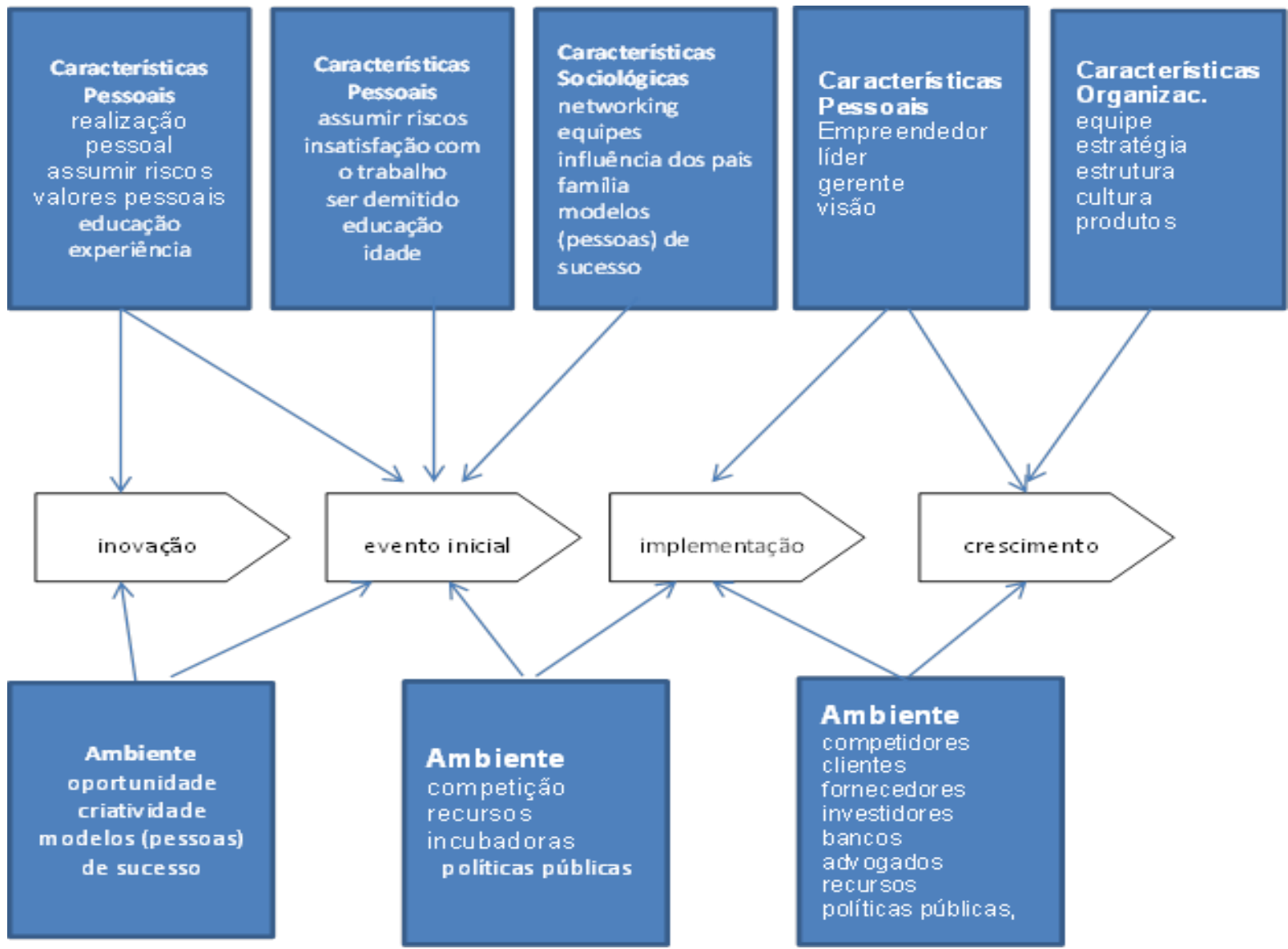

Figura 1 - Modelo do processo empreendedor

Fonte: Bygrave (2004)

Com vistas a aperfeiçoar tal abordagem, Nassif, Ghobril e Silva (2010) apresentaram um modelo de processo empreendedor por meio da identificação das dimensões afetivas e cognitivas nas ações empreendedoras durante as fases de inovação, início do negócio, implementação e crescimento do empreendimento. O modelo (Figura 2) indica o desenvolvimento dos atributos do empreendedor por meio de novas capacidades à medida que o negócio expande em tamanho e complexidade.

SILVA, W. A. L.; FONSECA, R. A. F.; ARAUJO, E. A. T. A. Comportamento empreendedor e trajetória empresarial de fundadores de MPES em Barão de Cocais/MG. Revista de Empreendedorismo e Gestão de Pequenas Empresas, v.4, n.2, 2015. 


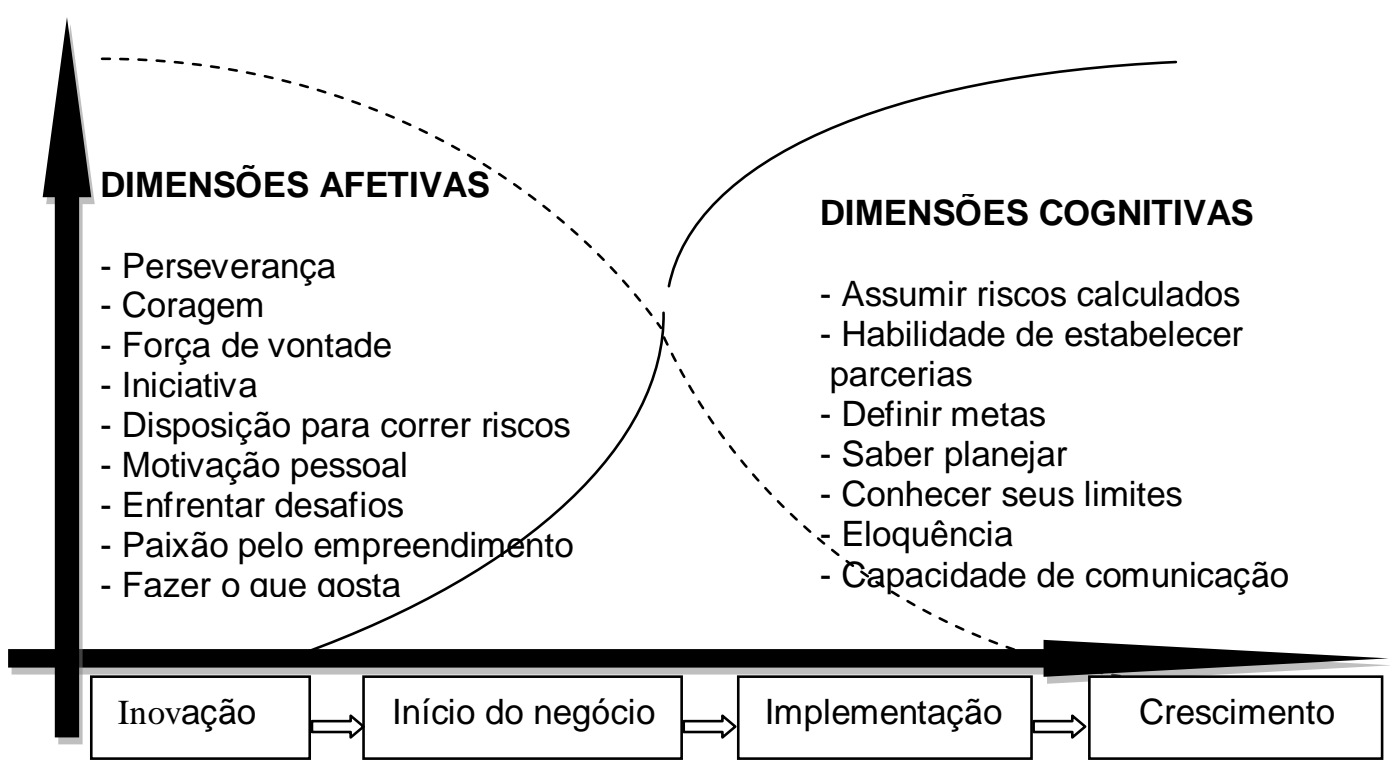

Figura 2 - Dinâmica do processo empreendedor

Fonte: Nassif, Ghobril e Silva (2010).

Dessa maneira, as modelagens mais atuais buscam incorporar novas vertentes ao modelo básico, como as dimensões afetivas e cognitivas, de maneira a considerar as perspectivas psicológica e comportamental dos empreendedores, o que ajuda a compreender melhor suas trajetórias empresariais.

\section{Antecedentes sobre comportamento empreendedor}

No Quadro 1 são compiladas algumas pesquisas empíricas que abordaram o comportamento empreendedor:

SILVA, W. A. L.; FONSECA, R. A. F.; ARAUJO, E. A. T. A. Comportamento empreendedor e trajetória empresarial de fundadores de MPES em Barão de Cocais/MG. Revista de Empreendedorismo e Gestão de Pequenas Empresas, v.4, n.2, 2015. 
Quadro 1 - Trabalhos anteriores sobre CCEs

\begin{tabular}{|c|c|c|}
\hline $\begin{array}{c}\text { Autor } \\
\text { (es)/Ano }\end{array}$ & Objetivo & Considerações \\
\hline $\begin{array}{c}\text { Petry e } \\
\text { Nascimento } \\
(2009)\end{array}$ & $\begin{array}{l}\text { Capturar as características mais } \\
\text { presentes no modelo de gestão } \\
\text { das empresas familiares, para } \\
\text { identificar as que explicam sua } \\
\text { longevidade, sob o enfoque do } \\
\text { processo sucessório. }\end{array}$ & $\begin{array}{l}\text { Nas organizações de menor porte, as } \\
\text { características divergem, em parte, das } \\
\text { recomendadas pela literatura. } \\
\text { Inexistiram evidências contundentes } \\
\text { sobre se determinantes da continuidade } \\
\text { das firmas. }\end{array}$ \\
\hline $\begin{array}{l}\text { Maciel } \\
(2009)\end{array}$ & \begin{tabular}{lcr} 
Checar a & validade & da \\
segmentação & entre & 0 \\
comportamento & empreendedor de \\
outras & \multicolumn{2}{c}{ capacidades } \\
organizacionais para explicar & 0 \\
desempenho empresarial. \\
\end{tabular} & $\begin{array}{l}\text { Existiu impacto positivo do } \\
\text { comportamento e das potencialidades } \\
\text { organizacionais no desempenho, e } \\
\text { relação causal e demanda por } \\
\text { hierarquização entre essas capacidades } \\
\text { e o comportamento. }\end{array}$ \\
\hline $\begin{array}{l}\text { Martinelli e } \\
\text { Fleming } \\
(2010)\end{array}$ & $\begin{array}{lcr}\text { Analisar a } & \text { influência de } \\
\text { características } & \text { emocionais no } \\
\text { comportamento } & \text { empreendedor } \\
\text { voltado a empreender. }\end{array}$ & $\begin{array}{l}\text { A ação de empreender mostrou-se mais } \\
\text { intensa naqueles com maior motivação } \\
\text { ancorada em seus elementos } \\
\text { emocionais de lócus de controle interno } \\
\text { e, também, que com maior } \\
\text { independência. }\end{array}$ \\
\hline $\begin{array}{c}\text { Maciel e } \\
\text { Camargos } \\
(2010)\end{array}$ & $\begin{array}{ll}\text { Estudar a } & \text { relação entre } \\
\text { comportamento } & \text { empreendedor, } \\
\text { lócus de controle e desempenho } \\
\text { organizacional. }\end{array}$ & $\begin{array}{l}\text { Ocorreu repercussão negativa de lócus } \\
\text { de controle externo sobre desempenho; } \\
\text { positiva, de lócus interno sobre } \\
\text { comportamento empreendedor e do } \\
\text { comportamento sobre o desempenho. }\end{array}$ \\
\hline $\begin{array}{c}\text { Della Bruna } \\
\text { Junior et al. } \\
\text { (2012) }\end{array}$ & \begin{tabular}{l}
\multicolumn{2}{c}{ Elaborar um processo que auxilie } \\
a identificação dos aspectos a \\
serem desenvolvidos pelas \\
empresas e empreendedores para \\
estimular a evolução dos \\
negócios.
\end{tabular} & $\begin{array}{l}\text { A abordagem apresentou-se eficaz na } \\
\text { identificação de ações potenciais que } \\
\text { facilitem o empreendimento atingir a } \\
\text { situação desejada. }\end{array}$ \\
\hline $\begin{array}{l}\text { Silva, } \\
\text { Chagas e } \\
\text { Siqueira } \\
(2012) \\
\end{array}$ & $\begin{array}{l}\text { Visualizar as características do } \\
\text { empreendedorismo internacional } \\
\text { ligadas à internacionalização da } \\
\text { Menendez Amerino. }\end{array}$ & $\begin{array}{l}\text { As relações que a gerência tinha foram } \\
\text { essenciais na internacionalização. E, } \\
\text { aspectos como a localização, clima etc. } \\
\text { impulsionaram a empresa. }\end{array}$ \\
\hline $\begin{array}{c}\text { Clemente e } \\
\text { Almeida } \\
(2013)\end{array}$ & \begin{tabular}{lll} 
Identificar as & \multicolumn{1}{c}{ características } \\
comportamentais & & \\
empreendedoras & (CCEs) de & um \\
empreendedor & varejista & de \\
eletrodomésticos. & & \\
ela & &
\end{tabular} & $\begin{array}{l}\text { Foram destaque: comprometimento; } \\
\text { exigência de qualidade e eficiência; } \\
\text { busca de informações e independência } \\
\text { e autoconfiança, com ações de } \\
\text { estratégia de posicionamento por } \\
\text { concorrente. }\end{array}$ \\
\hline $\begin{array}{l}\text { Klein, Alves } \\
\text { e Pereira } \\
(2013)\end{array}$ & $\begin{array}{l}\text { Estudar as características } \\
\text { empreendedoras e valores dos } \\
\text { gestores e colaboradores das } \\
\text { empresas da Incubadora } \\
\text { Tecnológica de Santa Maria. }\end{array}$ & $\begin{array}{l}\text { Sinalizaram-se pelas quais: realização e } \\
\text { inovação; conhecimentos técnicos; } \\
\text { formação complementar e escolaridade; } \\
\text { flexibilidade e valoração das } \\
\text { oportunidades; valores éticos, lealdade } \\
\text { e autenticidade; necessidades de }\end{array}$ \\
\hline
\end{tabular}

SILVA, W. A. L.; FONSECA, R. A. F.; ARAUJO, E. A. T. A. Comportamento empreendedor e trajetória empresarial de fundadores de MPES em Barão de Cocais/MG. Revista de Empreendedorismo e Gestão de Pequenas

Empresas, v.4, n.2, 2015. 
desenvolvimento.

Moraes, $\quad$ Diferenciar as características do Os motoristas autônomos mostraramHashimoto e perfil empreendedor de motoristas se aqueles mais empreendedores. Albertini do transporte rodoviário de carga. Houve influências de uma característica

(2013) empreendedora sobre outra.

Fonte: Elaborado pelos autores.

A maior parcela dos artigos obtidos focou em atestar elementos acerca do comportamento empreendedor. Portanto, é um tema recorrente e demanda esforços para solidificar conhecimentos sobre os comportamentos dos empreendedores que têm facilitado a longevidade das MPEs.

\section{Procedimentos metodológicos}

Esta pesquisa caracteriza-se como empírico-descritiva-qualitativa e utiliza dados primários (COLLIS; HUSSEY, 2005). Seu objetivo é identificar as CCEs presentes nos fundadores de empresas que influenciam sua trajetória empresarial no município de Barão de Cocais/MG a partir do modelo de Bygrave (2004).

Trata-se de um estudo de casos múltiplos, por investigar a situação com diversas unidades de interesse. O estudo de caso avalia um fenômeno contemporâneo no seu ambiente empírico, sobremaneira, se os limites entre o fenômeno e o contexto estão indefinidos. Aquele de múltiplos pode incluir mais de um caso unitário. Busca-se o entendimento de replicações teóricas e literais. Um exemplo seria dois ou mais casos que se julga serem replicações literais como diversos casos com resultados exemplares à luz de alguma teoria (YIN, 2005).

As unidades de observação foram MPEs localizadas no município de Barão de Cocais/MG. Os sujeitos da pesquisa foram os fundadores dessas MPEs. Os sujeitos foram selecionados pelo critério intencional. A intencionalidade na escolha dos sujeitos pode ser representada como aqueles

SILVA, W. A. L.; FONSECA, R. A. F.; ARAUJO, E. A. T. A. Comportamento empreendedor e trajetória empresarial de fundadores de MPES em Barão de Cocais/MG. Revista de Empreendedorismo e Gestão de Pequenas Empresas, v.4, n.2, 2015. 
indivíduos que são encontrados e dispõem de tempo para conceder as entrevistas (TRIVINÕS, 1987).

O número de empreendedores entrevistados foi determinado pelo critério de saturação dos dados. Foram realizadas entrevistadas até se atingir a saturação dos dados, alcançada com 9 empreendedores (doravante denominados E1, E2, E3, E4, E5, E6, E7, E8 e E9). O processo de saturação ocorre quando, na percepção do pesquisador, é decidido que novos sujeitos passam a não contribuir significativamente ao aprimoramento da reflexão teórica, caracterizando a repetição das informações coletadas (DENZIN; LINCOLN, 1994). Logo, a partir da constatação da saturação, decidiu-se não entrevistar outros sujeitos.

A técnica de coleta de dados utilizada foi um roteiro de entrevista semiestruturada, elaborado por Fernandes (2013). Este tipo de instrumento foi escolhido pela flexibilidade de repetir ou esclarecer algumas perguntas, além de permitir a avaliação de uma linguagem não verbal dos entrevistados. Consiste em um dos principais meios para coletar os dados na abordagem qualitativa, pois enriquece a pesquisa ao permitir que o investigador explore todas as perspectivas do entrevistado. É um instrumento que inicia com questionamentos básicos, alicerçados em teorias e, em seguida, oferece um vasto campo de interrogativas que surgem no decorrer da entrevista (TRIVINÕS, 1987).

O roteiro de Fernandes (2013) foi segmentado em duas partes: a) as características pessoais, sociológicas, organizacionais e ambientais que afetam o processo empreendedor, seguida pela síntese dos resultados e caracterização dos entrevistados e das empresas; e b) resumo do modelo do processo empreendedor constando as CCEs.

As entrevistas foram realizadas durante o mês de junho de 2014, com duração média de 50 minutos. Todas foram gravadas com autorização prévia dos entrevistados. Estes foram informados sobre o tema da pesquisa e a garantia de privacidade acerca de seus nomes.

SILVA, W. A. L.; FONSECA, R. A. F.; ARAUJO, E. A. T. A. Comportamento empreendedor e trajetória empresarial de fundadores de MPES em Barão de Cocais/MG. Revista de Empreendedorismo e Gestão de Pequenas Empresas, v.4, n.2, 2015. 
Após a coleta de dados, as entrevistas foram transcritas por um assistente de pesquisa, mantendo as informações repassadas por cada entrevistado. Os dados foram apresentados de forma estruturada e analisados a partir categorias de análise temáticas elaborada pelo pesquisador. Para ilustrar a apresentação dos resultados, foram utilizados alguns relatos de entrevistas.

As informações obtidas foram avaliadas por meio de análise de conteúdo temática, que consiste em um conjunto de técnicas para examinar informações via procedimentos sistemáticos para descrição das mensagens emitidas, visando fazer inferências a partir da interpretação dessas mensagens (BARDIN, 2006).

Em resumo, as fases para a avaliação foram: i) transcrição das entrevistas; ii) leitura dessas transcrições; iii) escolha das assertivas de interesse; iv) determinação das unidades de conteúdo; v) recorte das assertivas por unidades; vi) agregação das unidades por temas; e vii) redação das unidades.

Os resultados são apresentados na próxima seção.

\section{Caracterização dos resultados das empresas e entrevistados}

Dentre os nove empreendedores entrevistados em Barão de Cocais/MG, a distribuição etária dos respondentes corresponde a $11 \%$ dos entrevistados com menos de 30 anos, 55\% entrevistados com idade entre 30 e 50 anos, e 33\% têm acima de 50 anos. Quanto ao gênero, pode-se observar que a maioria dos sujeitos são homens (55\%) e 44\% são mulheres.

Quanto à escolaridade, nota-se que 33\% possuem o Ensino Médio completo, 22\% estão cursando o Ensino Superior e 44\% já possuem curso superior completo.

Destes, $77 \%$ relataram que o atual empreendimento é o primeiro em suas vidas de empreendedores e $22 \%$ relataram que já tiveram outros negócios. Em relação aos empreendimentos anteriores, um dos SILVA, W. A. L.; FONSECA, R. A. F.; ARAUJO, E. A. T. A. Comportamento empreendedor e trajetória empresarial de fundadores de MPES em Barão de Cocais/MG. Revista de Empreendedorismo e Gestão de Pequenas Empresas, v.4, n.2, 2015. 
empreendedores evidenciou já ser o quarto negócio e o outro apontou que é seu segundo empreendimento.

Sobre a atuação da empresa, 66\% trabalham no comércio, $22 \%$ com prestação de serviços e $11 \%$ possuem quatro empresas e, por isso, atuam no comércio e na área de prestação de serviço, cumulativamente.

No tocante ao ramo de atuação, são os seguintes: farmacêutico, rede de materiais de construção, comércio varejista de combustíveis, ótica, confecção e calçados, lanchonete e restaurante, construção civil e informática.

Todos os entrevistados têm sócios no empreendimento. Para 66\%, 0 sócio é uma pessoa da família. Quanto ao tempo de fundação, 44\% dos empreendimentos têm menos de 20 anos, 33\% têm entre 24 e 30 anos e 22\% possuem acima de 30 anos de existência. Ainda, 66\% têm até 30 funcionários, $22 \%$ têm entre 32 a 52 empregados e 11\% tem 160 colaboradores.

\section{Trajetória empresarial a partir dos fatores pessoais, sociológicos, organizacionais e ambientais que influenciam o processo empreendedor}

Para compreender o fenômeno do empreendedorismo com o objetivo de estimular seu crescimento, é necessário entender o processo pelo qual as novas organizações nascem (GARTNER, 1988). O empreendedorismo tem importância vital para o desenvolvimento econômico (BYGRAVE, 2004). O empreendedor é principal ator responsável pela evolução do empreendimento (ENOQUE, 2014). Na avaliação do empreendedorismo, as práticas utilizadas pelos empreendedores adquiriram destaque (STEYAERT, 2007).

A literatura tem descrito que o evento empreendedor amplia-se em função da força de um indivíduo que sabe concentrar-se nas oportunidades do seu ambiente e as transforma em resultados por meio da criação de uma organização. Assim, os precedentes de um evento empreendedor são junção das forças de um indivíduo e do ambiente diante da percepção da oportunidade (ANDERSON, 2000).

SILVA, W. A. L.; FONSECA, R. A. F.; ARAUJO, E. A. T. A. Comportamento empreendedor e trajetória empresarial de fundadores de MPES em Barão de Cocais/MG. Revista de Empreendedorismo e Gestão de Pequenas Empresas, v.4, n.2, 2015. 
Durante os relatos dos entrevistados, foram expostos fatores que determinaram a abertura dos empreendimentos. Dos nove respondentes, quatro indicaram que a oportunidade de negócio foi um fator determinante:

Porque a gente viu necessidade né?! De ampliar um pouquinho mais e [...] sair do supermercado que era nosso ramo anterior e [...] partir para o material de construção que estava necessitando na cidade na época né?! (E03)

No percurso da trajetória empresarial, as organizações procuram analisar $\mathrm{O}$ ambiente em que estão inseridas e adaptam-se às peculiaridades (PINHEIRO; SILVA; ARAÚJO, 2013). Neste sentido, observa-se que a carência de certos empreendimentos na cidade, foi apontada como o motivo precípuo para a constituição dessas empresas. Outros dois apontaram a oportunidade percebida em que a necessidade foi determinante para a abertura do negócio:

Eu comecei [...], logo após o falecimento do meu marido, eh [...]. Eu já vendia roupas, né, mais naquele [...] esquema de sacoleira mesmo, tá! Então, com a morte dele eu fiquei meio que perdida. Porque [...], eu trabalhava na fazenda [...] como retaguarda mesmo, eu era meio motorista, meio cozinheira [...]. (E07)

[...] quando a empresa que eu trabalhava antes, tava fechando [...]. (E09)

Segundo Bygrave (2004), as experiências anteriores são capazes de determinar novas ideias que podem viabilizar oportunidades de negócio. Assim, as variáveis "experiência prévia" e "satisfação no trabalho" podem agregar na formação e influência para o desenvolvimento do negócio. Na presente pesquisa, as variáveis "experiência do sócio" e "gostar da profissão" foram citadas por um empreendedor.

A ótica era porque [...] a experiência que o meu outro sócio tinha, entendeu? Aí eu aproveitei essa experiência [...]. Dele, porque ele já vinha do ramo de ótica, que o pai dele também tem ótica em Itabira [...]. (E06)

SILVA, W. A. L.; FONSECA, R. A. F.; ARAUJO, E. A. T. A. Comportamento empreendedor e trajetória empresarial de fundadores de MPES em Barão de Cocais/MG. Revista de Empreendedorismo e Gestão de Pequenas Empresas, v.4, n.2, 2015. 
A pesquisa sinalizou pouca relevância da variável "realização pessoal", pois apenas um empresário declarou que um dos motivos que o estimulou a empreender foi o "gostar da profissão" e a decisão de constituir o empreendimento tem relação com a experiência anterior como responsável técnico por duas farmácias, aliado à influência familiar, uma vez que o empresário relatou que seu pai e avó foram farmacêuticos.

McClelland (1961) realizou uma pesquisa para estudar o comportamento empreendedor e concluiu que os indivíduos com alta necessidade de realização estão mais propensos para as atividades empreendedoras. Dessa forma, os resultados obtidos divergem daqueles enunciados por McClelland (1961).

Uma possível razão pode estar relacionada às características do município de Barão de Cocais, em que a economia baseia-se em um baixo número de profissões, restringindo a escolha de seus moradores. Isso pode ser decisivo para vislumbrarem as oportunidades em detrimento da realização pessoal, embora esta possa acontecer em função do sucesso dos negócios.

A variável "assumir riscos" é percebida de maneira diferenciada pelos empreendedores. Dos nove entrevistados, sete afirmaram reconhecer os riscos e para minimizá-los, utilizam algumas ações como novos investimentos, treinamento de funcionários, financiamento próprio e manutenção de clientes. Houve um relato que se diferenciou ao considerar que o país está em uma situação de estabilidade e, por isso, não percebe os riscos do empreendimento.

Sempre em alerta [...] sempre baseado nos números [...]. (E09) O risco é o dia a dia [...]. (E01)

Analisando os relatos sobre essa variável, é possível perceber que três entrevistados realizam investimentos sempre pensando nos riscos. Os empresários demonstram que trabalham em um sistema de vendas a prazo e convivem com o risco diariamente.

Dos nove sujeitos, cinco sinalizaram que o principal ponto que

SILVA, W. A. L.; FONSECA, R. A. F.; ARAUJO, E. A. T. A. Comportamento empreendedor e trajetória empresarial de fundadores de MPES em Barão de Cocais/MG. Revista de Empreendedorismo e Gestão de Pequenas Empresas, v.4, n.2, 2015. 


\section{Rigrep A Revista da ANEGEPE

caracteriza o sucesso do empreendimento é a variável "clientes" e para conquistar e manter a satisfação desse público prioriza o respeito e qualidade no atendimento. Os discursos de quatro entrevistados apontam a mão de obra do negócio como garantia de sucesso, por isso, investem em mão de obra qualificada.

Percebe-se, portanto, que a variável "clientes" está relacionada com uma equipe de trabalho adequada, pois três empresários que atribuíram ao cliente ser o fator de sucesso, indicaram que isso depende da contribuição dos funcionários.

[...] eu falo muito com os meus funcionários [...]. É o cliente chegar, é tratar bem, é sorrir, é abraçar [...] não tem o medicamento agora, eu pego em outra farmácia emprestado, eu corro atrás [...]. (E04)

É, comunicação, respeito com o consumidor, tratar bem a pessoa [...] (E01).

[...] é eu ser linha de frente no negócio, qualidade dos produtos, atendimento espetacular e [...]. Uma boa eficiência no trabalho mesmo do cliente, uma boa mão de obra [...]. (E08)

De acordo com Drucker (1986), a inovação pode ser aprendida por meio de uma disciplina e consiste no principal meio para os empreendedores alcançarem oportunidades de negócio. A criatividade só tem relevância quando a empresa centra-se nos resultados. Então, a invenção de processos ou de produtos seria fundamental para assegurar o negócio, atendendo as demandas dos clientes conforme surgirem (FALLON; SENN, 2006).

A partir disso, a cultura da inovação tende a repercutir no desempenho das organizações (DOBNI, 2008). Essa cultura associa-se com a gestão do conhecimento, sendo um condicionante da inovação sustentável e do desempenho organizacional (JANIUNAITE; PETRAITE, 2010). Tudo isso possui relação com o empreendedorismo, uma teoria de crescimento econômico em que a inovação é o elemento prevalente na elaboração de novos produtos (ou serviços) e no fomento ao interesse em investir nos novos

SILVA, W. A. L.; FONSECA, R. A. F.; ARAUJO, E. A. T. A. Comportamento empreendedor e trajetória empresarial de fundadores de MPES em Barão de Cocais/MG. Revista de Empreendedorismo e Gestão de Pequenas Empresas, v.4, n.2, 2015. 
negócios (HISRICH; PETERS; SHEPHERD, 2009).

Dos respondentes, quatro indicaram que percebem a inovação como busca de conhecimento para alcançar o crescimento do negócio. A inovação foi mencionada pelos respondentes como sinônimo de mudanças.

É [...] inovação é aquela coisa que a gente não pode ficar sempre naquela mesma condição de trabalho, sendo que tem que procurar cada dia mais fazer curso, aperfeiçoar, melhorar, porque isso faz com que você inovando e mude muitas coisas do seu dia a dia, você inovando você abre espaço para crescer. (E01)

A inovação [...]. É você procurar sempre o que há de melhor no mercado, né! (E06)

Para Drucker (1986), a inovação pode ser caracterizada como algo novo no empreendimento que o diferencie dos demais. No ambiente organizacional, é reflexo de comportamentos ou atividades ligados a atitudes ou resultados tangíveis (DOBNI, 2008). Qualquer tipo de alteração no produto, na prestação de serviço ou no processo produtivo, que cause ruptura ao método anteriormente utilizado pela empresa e que agregue valor, pode ser considerado inovação.

Ao serem questionados sobre as inovações em seus empreendimentos, cinco respondentes mencionaram a mudança no layout como a principal inovação, seguida pela diversificação dos produtos para atender o maior número de clientes (por dois sujeitos). Um entrevistado indicou que sua inovação foi o convênio para atender grandes empresas.

Segundo McClelland (1961), uma das características do comportamento empreendedor refere-se a criar metas a curto e longo prazo. Todos os entrevistados indicaram que planejam o crescimento do empreendimento, mas somente cinco relataram ter expectativas e metas definidas. Ainda assim, outras características são definidas por Filion (1999), Bygrave (2004), Dolabela (2008), Nassif, Ghobril e Silva (2010) e Della Bruna Junior (2012).

SILVA, W. A. L.; FONSECA, R. A. F.; ARAUJO, E. A. T. A. Comportamento empreendedor e trajetória empresarial de fundadores de MPES em Barão de Cocais/MG. Revista de Empreendedorismo e Gestão de Pequenas Empresas, v.4, n.2, 2015. 
[...] devo crescer em 2015 em torno de 15 a 20, talvez até $25 \%$ a nível de geração de negócios [...]. (E02)

Aumentar, talvez até abrir mais algumas unidades nas cidades vizinhas [...]. (E03)

Um dos motivos apontados por dois empreendedores pela ausência da expectativa de crescimento é a situação econômica do país e a incerteza sobre a permanência do empreendimento em atividade. Um dos entrevistados relatou que não tem expectativa de crescimento, pois o negócio já está na fase de estabilidade.

Tal fase é abordada por teorias do ciclo de vida organizacional, como da maturidade e da pós-maturidade (e.g. ADIZES, 1990; MILLER; FRIESEN, 1984; GREINER, 1998). Para Adizes (1990), a primeira fase do estágio de envelhecimento da empresa é caracterizada pela perda de flexibilidade, conforto, preocupação decrescente com o futuro, assume-se menos riscos, há maior interesse nas relações interpessoais e expectativas menores de crescimento

Diferentemente de Greiner (1998), o qual aponta a renovação como um relevante mecanismo de transformação, Adizes (1990) aponta que as empresas estagnam e iniciam um longo período com os mesmos produtos, serviços e estruturas. Assim, pode ser o início do declínio do negócio, já que há despreocupação em realizar melhorias. Isso tende a prejudicar a sobrevivência do negócio, podendo levá-la à mortalidade e acarretar aumento de desemprego e queda na geração de renda.

Cabe salientar que as atividades empreendedoras influenciam bastante a economia de uma localidade, sendo pilares econômicos e criadoras de empregos (HISRICH; PETERS; SHEPHERD, 2009).

[...] agora sonhando na expectativa de sair da copa e entrar na eleição, e vê se vai melhorar alguma coisa. (E01)

[...] baixa, muito baixa a expectativa, se for realista mesmo [...] nosso negócio é viável pra no máximo dois anos [...]. (E09)

SILVA, W. A. L.; FONSECA, R. A. F.; ARAUJO, E. A. T. A. Comportamento empreendedor e trajetória empresarial de fundadores de MPES em Barão de Cocais/MG. Revista de Empreendedorismo e Gestão de Pequenas Empresas, v.4, n.2, 2015. 
[...] o meu comércio ele tá numa estabilidade, eu não tenho como crescer mais o meu espaço físico e o financeiro ele vai de acordo com a economia do nosso país. (E07)

No que toca a sobrevivência do empreendimento, oito entrevistados relataram que existem motivos que podem ameaçar a sobrevivência do empreendimento. Os principais fatores foram: a condição econômica do país, a venda a prazo, a concorrência com as grandes empresas e redes, os interesses divergentes nas empresas familiares, a falta de parceira entre os concorrentes e o fácil acesso à tecnologia.

Os grandes mercados, sempre vai ser os grandes mercados, as grandes empresas [...]. Hoje, as empresas se tornam cada vez mais parceiras, se tornam cada vez maiores [...]. (E02)

[...] condição econômica do país mesmo, a gente às vezes fica meio apreensivo, a gente não sabe o que vai acontecer amanhã [...] a gente tem um pouco de medo da condição econômica. (E03)

Todos os respondentes evidenciaram que foi preciso trabalhar a liderança em algum momento do empreendimento. O principal período apontado por quatro deles, foi no treinamento da equipe. Três entrevistados retrataram que foi no início do empreendimento que necessitaram buscar conhecimento sobre o negócio. Para outros três, o empreendedor está a todo o momento trabalhando a liderança.

[...] foi no princípio de 1982 a, 1982 a 1986 por aí, porque foi no ano, nos anos que a gente precisou trabalhar captando gente [...]. (E01)

Todos os dias! A liderança ela tem que tá agregada a postura, a empreendimento, a mudança, sabe? (E07)

Quanto às parcerias no negócio, oito sujeitos indicaram cultivá-las. Destes, sete mantêm-nas com fornecedores, dois entrevistados com membros da família, dois com funcionários e um com empreendedores de outras áreas.

SILVA, W. A. L.; FONSECA, R. A. F.; ARAUJO, E. A. T. A. Comportamento empreendedor e trajetória empresarial de fundadores de MPES em Barão de Cocais/MG. Revista de Empreendedorismo e Gestão de Pequenas Empresas, v.4, n.2, 2015. 
Em relação à colaboração dessas parcerias para o empreendimento, quatro assinalaram que a relação agrega ao negócio, três sugeriram que agregam muito e um declarou que algumas parcerias agregam.

Todos os meus fornecedores eles não são só fornecedores, eles são parceiros. Todos os meus funcionários eles são parceiros. (E07)

[...] nessa parceria então a gente consegue comprar o custo, benefício do medicamento mais baixo ainda. (E01)

Foi possível perceber algumas justificativas para a percepção positiva da parceria, como a possibilidade de maior valor de compra, melhoria na relação de confiança, orientação quanto a melhores preços, pontualidade na entrega, ajuda na concepção de novas ideias para o negócio e melhoria no relacionamento com empresas com credibilidade mundial.

Todos os entrevistados demonstraram conviver com os obstáculos e desafios de forma contínua. A concorrência foi a principal dificuldade enfrentada por três deles. Já a concorrência desleal, as contingências do mercado e a dificuldade de trabalhar com o público, foram o segundo empecilho apontado por dois. Outros dois disseram da falta de incentivo do poder público às pequenas empresas, o elevado custo de tributação, a rotatividade de funcionários em função da atratividade salarial e benefícios oferecidos pelas grandes empresas. A falta de parceria dos colaboradores foi apontada por um respondente.

[...] os desafios são essa concorrência desleal de pessoas, por exemplo, que não pagam impostos, não está preocupado, por exemplo, com a vigilância sanitária [...]. O segundo são as questões tributárias, ninguém aguenta, essa questão tributária hoje no Brasil tá deixando o empresariado sem saber o que fazer. O custo hoje de tributação que você tem é muito alto [...]. (E08)

Sobre a idealização do negócio, seis entrevistados esclareceram que sonhavam em abrir um empreendimento, mas metade idealizava um tipo de

SILVA, W. A. L.; FONSECA, R. A. F.; ARAUJO, E. A. T. A. Comportamento empreendedor e trajetória empresarial de fundadores de MPES em Barão de Cocais/MG. Revista de Empreendedorismo e Gestão de Pequenas Empresas, v.4, n.2, 2015. 
negócio diferente do constituído. A influência da família parece ter uma forte contribuição na idealização do negócio na vida de três entrevistados. Os empreendedores relataram que a família influenciou na decisão de abrir o próprio negócio, principalmente, pela experiência.

Essa influência é apontada como uma variável que favorece a formação de empreendedores (SHAPERO; SOKOL, 1982). Bygrave (2004) reforça essa ideia argumentando que, se o indivíduo tem um parente próximo que é empreendedor, é mais provável que exista o desejo de torna-se empreendedor, sobretudo, se esse parente é o pai ou a mãe do indivíduo.

Sonhava em ter um estabelecimento para poder trabalhar e fazer o que meu pai fazia. É, viver com o povo, trabalhar com o povo, lidar com o povo no dia a dia, mas é claro, [...] eu não pensava assim grande não, eu pensava em ter uma farmácia e tal [...]. (E01)

A nossa família já tinha uma tradição de comércio mesmo, meu pai, meus tios, meus avós, a gente já vem, né? Assim de uma tradição de comércio mesmo [...]. (E03)

McClelland (1961) evidenciou em seu estudo sobre o comportamento empreendedor, o poder de persuasão e rede de contatos dos empreendedores, pois essas características são usadas para influenciar determinadas pessoas para que os objetivos empresariais sejam alcançados.

Todos os entrevistados indicaram alguma experiência positiva no empreendimento, sendo que as principais foram a credibilidade da empresa junto ao mercado, o bom resultado apresentado pela empresa e a melhoria no relacionamento com as pessoas.

[...] foi o resultado, o resultante foi aquilo que eu esperava e maior um pouco e o maior de todos mesmo foi a minha participação numa questão de mercado. Hoje a eu sou uma pessoa extremamente é [...] Influente, conhecida. (E08)

Todos os entrevistados apontaram alguns fatores que proporcionam satisfação no trabalho, dentre os quais: o sucesso do negócio, o prazer em

SILVA, W. A. L.; FONSECA, R. A. F.; ARAUJO, E. A. T. A. Comportamento empreendedor e trajetória empresarial de fundadores de MPES em Barão de Cocais/MG. Revista de Empreendedorismo e Gestão de Pequenas Empresas, v.4, n.2, 2015. 
poder ajudar a família e os clientes, o bom ambiente de trabalho e o feedback dos clientes. Todos disseram gostar do que fazem, um acredita estar no momento de descansar.

Não e nem financeiramente não, a realização de ter conseguido crescer [...] crescer e manter no mercado, né? Que isso é muito importante, que é manter no mercado. (E03)

Apenas seis empreendedores descreveram experiências negativas no empreendimento. Seus relatos focaram na dificuldade em conseguir crédito junto aos bancos, pouco domínio do negócio e dificuldade em lidar com os funcionários. Todos os entrevistados indicaram conviver com fatores que não gostam no empreendimento. Aqueles principais apresentados por três foram: a inadimplência dos clientes e a demissão de funcionários.

Então, no comércio de interior você trabalha assim, ao mesmo tempo que você se aproxima das pessoas você cria liberdade. E essas liberdades são transformadas em créditos e muitas vezes esses créditos não são pagos [...]. (E08)

A parte que eu não gosto aqui [...] é a parte que é mais difícil pra mim [...] (risos) é demissão de funcionários, eu acho [...] muito difícil você [...] demitir um funcionário. Você tem que falar com ele o que ele não se adequou a empresa, porque que ele não se adequou [...]. (E04)

Todos mencionaram situações difíceis que os deixam tensos no empreendimento. As mais apontadas são: não conseguir honrar com os compromissos assumidos com os clientes, o atraso na entrega dos fornecedores e a dificuldade de pagar todas as despesas mensais. A falta de comprometimento dos funcionários foi considerada por quatro como a maior causa de tensão e irritação. Visualiza-se, então, que parte dessas situações decorre de insuficiência de planejamento e de utilização de ferramentas apropriadas para prevenir ou resolver tais problemas.

SILVA, W. A. L.; FONSECA, R. A. F.; ARAUJO, E. A. T. A. Comportamento empreendedor e trajetória empresarial de fundadores de MPES em Barão de Cocais/MG. Revista de Empreendedorismo e Gestão de Pequenas Empresas, v.4, n.2, 2015. 
Comprometimento com as entregas. Eu sou rigoroso, [...] eu sou extremamente pontual, sou extremamente pontual dentro [...] dos meus horários, dos meus comprometimentos, se eu falar que eu vou entregar em tal data um produto é tal data e cobro isso permanentemente dos meus funcionários, 0 comprometimento com as datas e com os seus compromissos [...]. (E04)

Ao serem questionados sobre o processo de tomada de decisão, quatro indicaram que procuram conversar com seus funcionários antes da tomada de decisão, dois disseram que não tem hábito de trocar informações com funcionários e dois mencionaram que as decisões são tomadas juntamente com os sócios, pensadas e baseadas nos números.

[...] primeiro com informação, né! Segundo em cima de uma legislação que cobre o nosso país, né! $\mathrm{E}$ terceiro, em parceria com os meus funcionários, nunca que eu tomo uma decisão que é só minha, eu gosto de ouvir, porque cada pessoa tem uma visão diferente. (E07)

Sobre os motivos que dificultam a tomada de decisão, três entrevistados citaram que não percebem dificuldade na tomada de decisão, dois indicaram que devido à dificuldade em lidar com o ser humano, o processo de tomada de decisão torna-se mais difícil. Dois entrevistados também mencionaram que têm dificuldades em lidar com opiniões diferentes das suas e precisam conviver com esta dificuldade porque o negócio é em sociedade.

Não! Não! [...] A partir do momento que você tem essa ideia de que você não tá sozinho, que você tem pessoas ali do seu lado que pode te ajudar muito mais do que você imagina, fica fácil demais [...]. (E07)

Não em sociedade! [...] tomada de decisão hoje [...] é a maneira que você pensa do negócio e o outro também pensa. Então, as decisões não sendo individuais fica difícil para você tomar essas decisões. (E06)

Mas, quando ocorre alguma situação inesperada, três empresários relataram que procuram manter a calma e outros três se sentem chateados e tensos. Isso sinaliza que as dimensões afetivas e cognitivas, inseridas no SILVA, W. A. L.; FONSECA, R. A. F.; ARAUJO, E. A. T. A. Comportamento empreendedor e trajetória empresarial de fundadores de MPES em Barão de Cocais/MG. Revista de Empreendedorismo e Gestão de Pequenas Empresas, v.4, n.2, 2015. 
modelo de Bygrave (2004), por intermédio do aprimoramento de Nassif, Ghobril e Silva (2010), encontram respaldo empírico, haja vista que são constatados no comportamento dos empreendedores.

[...] eu fico muito chateado e ansioso quando as coisas fogem ou não dá certo por algum motivo. (E08)

Inesperadas? [...] Essa é uma questão difícil [...] você tem que ter tranquilidade e sabedoria pra você agir nessa hora, calma!

A partir das respostas dos empreendedores, pode-se perceber que inexiste uniformidade na forma como cada um conduz os obstáculos e desafios do negócio. No entanto, foram encontradas características comportamentais comuns aos empreendedores, como a inovação, liderança, otimismo, iniciativa, habilidade de conduzir situações e utilizar recursos, confirmando a pesquisa sobre as características comuns aos empreendedores de Filion (1997).

\section{Considerações finais}

Esta pesquisa teve como objetivo identificar as CCEs presentes nos fundadores de empresas que influenciam suas trajetórias empresariais, no município de Barão de Cocais/MG, a partir do modelo de Bygrave (2004).

A partir da análise de conteúdo, foi possível perceber traços da trajetória empresarial dos entrevistados. Identificou-se que a convivência com modelos de pessoas empreendedoras na família aliada à percepção de uma oportunidade de negócio na cidade foram fundamentais na decisão de tornarse empreendedor.

Apesar de os sujeitos possuirem empreendimentos na mesma cidade, pode-se observar a inexistência de uniformidade na forma de gerenciar os negócios em função das diferentes CCEs, notadamente, na forma como tomam as decisões no empreendimento.

Apesar disso, as características comuns aos empreendedores SILVA, W. A. L.; FONSECA, R. A. F.; ARAUJO, E. A. T. A. Comportamento empreendedor e trajetória empresarial de fundadores de MPES em Barão de Cocais/MG. Revista de Empreendedorismo e Gestão de Pequenas Empresas, v.4, n.2, 2015. 
encontradas foram: a inovação, liderança, otimismo, iniciativa, habilidade de conduzir situações e utilizar recursos. Já aquelas não visualizadas foram: insatisfação com o trabalho, ser demitido, idade, investidores, incubadoras e advogados.

Ao que parece, boa parte das características pessoais, sociológicas, organizacionais e ambientais interferem positivamente na formação do processo empreendedor, confirmando o modelo de Bygrave (2004). Também, apresentou subsídio empírico para confirmar o aperfeiçoamento de Nassif, Ghobril e Silva (2010), ao modelo básico de Bygrave, com a inserção das dimensões afetivas e cognitivas.

Assim, de forma geral, a pesquisa conseguiu atingir aos objetivos propostos ao identificar e analisar as CCEs em Barão de Cocais/MG que influenciam na trajetória empresarial, a partir do modelo do processo empreendedor de Bygrave (2004), reforçando a capacidade dessa teoria para compreender situações reais, bem como fortaleceu os achados de Fillion (1999). Por outro lado, divergiu de enunciados de MacClelland (1961).

Como colaboração à academia, os achados alimentam os debates sobre os aspectos que repercutem na trajetória dos empresários e se a teoria de Bygrave (2004) foi adequada para capturá-los. Para o mercado, fornece aos empreendedores o conhecimento de fatores presentes nos seus pares, dificuldades enfrentadas e benesses, permitindo que busquem instrumentos de planejamento e controle para contornar suas fraquezas e potencializar suas forças.

Em relação às limitações desta pesquisa, destaca-se a baixa disponibilidade de tempo dos entrevistados para colaborar com a investigação. Uma recomendação para trabalhos futuros é a realização de pesquisas utilizando o mesmo modelo, mas em outras localidades, permitindo, assim, comparativos.

SILVA, W. A. L.; FONSECA, R. A. F.; ARAUJO, E. A. T. A. Comportamento empreendedor e trajetória empresarial de fundadores de MPES em Barão de Cocais/MG. Revista de Empreendedorismo e Gestão de Pequenas Empresas, v.4, n.2, 2015. 


\section{Referências}

ADIZES, I. Os ciclos de vida das organizações: como e por que as empresas crescem e morrem e o que fazer a respeito. São Paulo: Pioneira, 1990.

ANDERSON, A. R. The protean entrepreneur: the entrepreneurial Process as fitting self and circunstance. Journal of Enterprising Culture, United Kingdom, v. 8 , p. 201-234, 2000.

BARDIN, L. Análise de conteúdo. Lisboa: Edições 70, 2006.

BARON, R. A.; SHANE, S. A. Empreendedorismo: uma visão do processo. São Paulo: Thomson Learning, 2007.

BARROS, F. S. O.; MOREIRA, M. V. C. O.; ENANPAD. O comportamento empreendedor e suas implicações: a organização produtiva de micro e pequenas empresas no turismo. In: ENCONTRO DA ASSOCIAÇÃO NACIONAL DE PÓS-GRADUAÇÃO E PESQUISA EM ADMINISTRAÇÃO, 29., 2005, Brasília. Anais... Rio de Janeiro: ANPAD, 2005.

BONCLER, J.; HLADY, M.; VERSTRAETE, T. Les équipes entrepreneuriales: cadrage théorique et proposition méthodologique. In: Congres International Francophone en Entrepreneuriat et PME, p. 1-25, 2006.

BORGES, A. F.; LIMA, J. B. O processo de construção da sucessão empreendedora em empresas familiares: um estudo multicaso. Revista de Empreendedorismo e Gestão de Pequenas Empresas, v. 1, n. 1, 2012.

BOSZCZOWSKI, A. K.; TEIXEIRA, R. M. O empreendedorismo sustentável e o processo empreendedor: em busca de oportunidades de novos negócios como solução para problemas sociais e ambientais. Revista Economia \& Gestão, v. 12, n. 29, p. 141-168, 2012.

BYGRAVE, W. D. The entrepreneurial process. In: BYGRAVE, W. D.; ZACHARAKIS, A. The portable MBA in entrepreneurship. Hoboken: John Wiley \& Sons, 2004.

CARNEIRO, P. P. Metodologia Fuzzy Aplicada para predição do comportamento empreendedor. In: ENCONTRO DA ASSOCIAÇÃO NACIONAL DE PÓS-GRADUAÇÃO E PESQUISA EM ADMINISTRAÇÃO, 32., 2008, Rio de Janeiro (RJ). Anais... Rio de Janeiro: ANPAD, 2008.

SILVA, W. A. L.; FONSECA, R. A. F.; ARAUJO, E. A. T. A. Comportamento empreendedor e trajetória empresarial de fundadores de MPES em Barão de Cocais/MG. Revista de Empreendedorismo e Gestão de Pequenas Empresas, v.4, n.2, 2015. 
CARPINTÉRO, J. N. $\quad$ C.; BACIC, M. J Empreendedorismo e desenvolvimento. Campinas: Instituto de Economia UNICAMP, 2001.

CLEMENTE, F. A. S.; ALMEIDA, P. M. Estratégias de posicionamento e características comportamentais empreendedoras: um estudo de caso de uma empresa do segmento de comércio varejista de eletrodomésticos no interior de MG. Teoria e Prática em Administração, v. 3 n. 1, p. 121-151, 2013.

COLLIS, J.; HUSSEY, R. Pesquisa em administração: um guia prático para alunos de graduação e pós-graduação. 2. ed. Porto Alegre: Bookman, 2005.

DELLA BRUNA JUNIOR, E. ENSSLIN, L.; ENSSLIN, S. R.; LEZANA, A. G. R.; GARCIA, J. R. Um diagnóstico empresarial sob a perspectiva do ciclo de vida organizacional e comportamento do empreendedor. Revista Gestão da Produção, Operações e Sistemas, n. 4, p. 25-41, 2012.

DENZIN, N. K., LINCOLN, Y. S. Handbook of qualitative research. Thousand Oaks: Sage, 1994.

DOBNI, C. B. Measuring innovation culture in organizations: the development of a generalized innovation culture construct using exploratory factor analysis. European Journal of Innovation Management, v. 11, n. 4, p. 539-559, 2008.

DOLABELA, F. O segredo de Luisa. São Paulo: Cultura, 2008.

DORNELAS, J. C. A. Empreendedorismo: transformando ideias em negócios. 2. ed. rev. e atual. Rio de Janeiro: Elsevier, 2005.

ENOQUE, A. G. Práticas de empreendedorismo em empresas familiares empreendedoras. In: ENCONTRO DA ASSOCIACCÃO NACIONAL DE PÓSGRADUAÇÃO E PESQUISA EM ADMINISTRAÇÃO, 38., 2014, Rio de Janeiro. Anais... Rio de Janeiro: ANPAD, 2014.

FALLON, P.; SENN, F. Juicing the orange. Harvard Business School Press, 2006.

FERNANDES, R. B. Características comportamentais empreendedoras: estudo da trajetória empresarial em empresas de pequeno porte na cidade de Brumadinho/MG. 136f. Dissertação (Mestrado em Administração) - Faculdade Novos Horizontes, Belo Horizonte, 2013.

SILVA, W. A. L.; FONSECA, R. A. F.; ARAUJO, E. A. T. A. Comportamento empreendedor e trajetória empresarial de fundadores de MPES em Barão de Cocais/MG. Revista de Empreendedorismo e Gestão de Pequenas Empresas, v.4, n.2, 2015. 
FERRARO, M. R. M. A Concepção de professores sobre saúde na escola. 124f. Dissertação (Mestrado em Ciências) - Faculdade de Medicina de Ribeirão Preto, Universidade de São Paulo, Ribeirão Preto, 2011.

FIALA, N. As Incubadoras como Ambientes de Aprendizagem do Empreendedorismo. In: ENCONTRO DA ASSOCIAÇÃO NACIONAL DE PÓSGRADUAÇÃO E PESQUISA EM ADMINISTRAÇÃO, 36, 2012, Rio de Janeiro. Anais... Rio de Janeiro: ANPAD, 2012.

FILION, L. J. Diferenças entre sistemas gerenciais de empreendedores e operadores de pequenos negócios. Revista de Administração de Empresas, v. 39 , n. 4 , p. 6-20, 1999.

FILION, L. J. Empreendedorismo e gerenciamento: processos distintos, porém complementares. Revista de Administração de Empresas, v. 40, n. 3, p. 8$17,2000$.

FILION, L. J. Empreendedorismo: empreendedores e proprietários-gerentes de pequenos negócios. Revista de Administração de Empresas, v. 34, n. 2, p. 5-28, 1999.

FILION, L. J. From entrepreneurship to entreprenology. In: USASBE ANNUAL NATIONAL CONFERENCE. 1997. Proceedings... Winsconsin: Usasbe, 1997.

GARTNER, W. B. A Conceptual framework for describing the phenomenon of new venture Creation. Academy of Management Review, v. 10, p. 696-706, 1985.

GARTNER, W. B. Who is an entrepreneur"? Is the wrong question. American Journal of Small Business, v. 12, p. 11-32, 1988.

GOMES, A. F.; LIMA, J. B.; CAPPELLE, M. C. A. Do empreendedorismo à noção de ações empreendedoras: reflexões teóricas. Revista Alcance, v. 20, n. 2, p. 203-220, 2013.

GREATTI, L. Perfis Empreendedores: Análise comparativa das trajetórias de sucesso e do fracasso empresarial no município de Maringá-PR. Revista FACEF Pesquisa-Desenvolvimento e Gestão, v. 8, n. 1, 2010.

GREINER, L. E. Evolution and revolution as organizations grow. Harvard Business Review, v. 76, n. 3, p. 55-67, 1998.

SILVA, W. A. L.; FONSECA, R. A. F.; ARAUJO, E. A. T. A. Comportamento empreendedor e trajetória empresarial de fundadores de MPES em Barão de Cocais/MG. Revista de Empreendedorismo e Gestão de Pequenas Empresas, v.4, n.2, 2015. 
HISRICH, R. D.; PETERS, M. P.; SHEPHERD D. A. Empreendedorismo. 7. ed. Porto Alegre: Bookman, 2009.

JANIUNAITE, B.; PETRAITE, M. The relationship between organizational innovative culture and knowledge sharing in organization: the case of technological innovation implementation in a telecommunication organization. Socialiniai Mokslai, v. 3, n. 69, p. 14-23, 2010.

JOHANNISSON, B. Towards a practice theory of entrepreneuring. Small Business Economics, v. 36, n. 2, p. 135-150, 2011.

KLEIN, L. L.; ALVES, J. N.; PEREIRA, B. A. D. Estudo da cultura empreendedora: as características empreendedoras e valores dos empresários e colaboradores da incubadora tecnológica de Santa Maria. Qualit@s Revista Eletrônica, v.14, n. 2, 2013.

MACIEL, C. O.; CAMARGO, C. Lócus de controle, comportamento empreendedor e desempenho de pequenas empresas. Revista de Administração Mackenzie, v. 11, n. 2, p. 168-188, 2010.

MACIEL, C. O. Comportamento empreendedor e capacidades organizacionais: hierarquização e mensuração de seus efeitos no desempenho de empresas de pequeno porte. Revista Alcance - Eletrônica, v. 16, n. 1, p. 26-44, 2009.

MARTINELLI, L. A. S.; FLEMING, E. S. O comportamento empreendedor: a influência das características emocionais na motivação dos indivíduos para a ação empreendedora. In: ENCONTRO DA ASSOCIAÇÃO NACIONAL DE PÓS-GRADUAÇÃO E PESQUISA EM ADMINISTRAÇÃO, 34, 2010, Rio de Janeiro. Anais... Rio de Janeiro: ANPAD, 2010.

McCLLELAND, D. C. The achieving society. Princeton, NJ: Van Nostrand, 1961.

MILLER, D.; FRIESEN, P. A longitudinal study of the corporate life cycle. Management Science, v. 30, n. 10, p. 1161-1183, 1984.

MORAES, M. J; HASHIMOTO, M.; ALBERTINE, T. Z. Perfil Empreendedor: estudo sobre características empreendedoras de motoristas funcionários, agregados e autônomos do transporte rodoviário de cargas. Revista de

SILVA, W. A. L.; FONSECA, R. A. F.; ARAUJO, E. A. T. A. Comportamento empreendedor e trajetória empresarial de fundadores de MPES em Barão de Cocais/MG. Revista de Empreendedorismo e Gestão de Pequenas Empresas, v.4, n.2, 2015. 
Empreendedorismo e Gestão de Pequenas Empresas, v. 2, n.1, p. 132-157, 2013.

MOROZ, P. W.; HINDLE, K. Entrepreneurship as a process: toward harmonizing multiple perspectives. Entrepreneurship Theory and Practice, v. 36 , n. 4, p. 781-818, 2012.

NASSIF, V. M. J.; GHOBRIL, A. N.; SILVA, N. S. Understanding the entrepreneurial process: a dynamic approach. Brazilian Administration Review, v. 7, n. 2, p. 213-226, 2010.

PETRY, L. I.; NASCIMENTO, A. M. Um estudo sobre o modelo de gestão e o processo sucessório em empresas familiares. Revista Contabilidade e Finanças, v. 20 n. 49, p. 109-125, 2009.

PINHEIRO, R. W;; SILVA, W. A. C.; ARAÚJO, E. A. T. Análise conjunta do ciclo de vida e da longevidade empresarial: um enfoque em indústria, comércio e agronegócio. Revista de Negócios, v. 18, n. 3, p. 37-57, 2013.

RONEN, J. Entrepreeurship - Some insights into the entrepreneurial process. Toronto: Lexingtonbooks, 1983.

SCHUMPETER, A. Teoria do desenvolvimento econômico: uma investigação sobre lucros, capital, crédito, juro e ciclo econômico. São Paulo: Nova Cultural, 1997.

SHAPERO, A.; SOKOL, L. The social dimensions of entrepreneurship. In: KENT, C. A.; SEXTON, D. L.; VESPER, K. H. (EDS). Encyclopedia of entrepreneurship. New Jersey: Prentice-Hall, 1982.

SILVA, I. M.; CHAGAS, A. C. C.; SIQUEIRA, S. V. Características de empreendedorismo internacional no processo de internacionalização: um estudo de caso na empresa Menendez \& Amerino. Internext - Revista Eletrônica de Negócios Internacionais da ESPM, v. 7, n. 2, p. 107-136, 2012.

STEYAERT, C. Entrepreneuring'as a conceptual attractor? A review of process theories in 20 years of entrepreneurship studies. Entrepreneurship and regional development, v. 19, n. 6, p. 453-477, 2007.

SILVA, W. A. L.; FONSECA, R. A. F.; ARAUJO, E. A. T. A. Comportamento empreendedor e trajetória empresarial de fundadores de MPES em Barão de Cocais/MG. Revista de Empreendedorismo e Gestão de Pequenas Empresas, v.4, n.2, 2015. 
TRIVIÑOS, A. N. S. Introdução à pesquisa em ciências sociais: a pesquisa qualitativa em educação. São Paulo: Atlas, 1987.

VIEIRA, M. M. F.; ZOUAIN, D. M. (org.). Pesquisa qualitativa em administração. Rio de Janeiro: FGV, 2004.

WATSON, T. J. Entrepreneurship in action: bringing together the individual, organizational and institutional dimensions of entrepreneurial action. Entrepreneurship \& Regional Development, v. 25, n. 5-6, p. 404-422, 2013.

YIN, R. K. Estudo de caso: planejamento e métodos. 3. ed. Porto Alegre: Bookman, 2005.

SILVA, W. A. L.; FONSECA, R. A. F.; ARAUJO, E. A. T. A. Comportamento empreendedor e trajetória empresarial de fundadores de MPES em Barão de Cocais/MG. Revista de Empreendedorismo e Gestão de Pequenas Empresas, v.4, n.2, 2015. 